\title{
Synthesis, Spectroscopic, and in Vitro Cytotoxic Studies of Fatty Acid Analogues of 2, 6-Diisopropylphenol
}

\author{
Ali Mohammad ${ }^{1 *}$, Fauzia B. Faruqi ${ }^{1}$, Jamal Mustafa ${ }^{2}$ \\ ${ }^{1}$ Department of Applied Chemistry, Faculty of Engineering and Technology, Aligarh Muslim University, Aligarh, India; ${ }^{2}$ Department \\ of Pharmacognosy, King Saud University, Riyadh, Kingdom of Saudi Arabia. \\ Email: alimohammad08@gmail.com
}

Received April 22 $2^{\text {nd }}, 2010$; revised May 21 ${ }^{\text {st }}, 2010$; accepted July $1^{\text {st }}, 2010$.

\begin{abstract}
This paper represents the synthesis, spectral analysis and in-vitro cytotoxic studies of some novel fatty acid anti-cancer conjugates of 2, 6-diisopropylphenol (propofol). Propofol is a potent intravenous hypnotic agent which is widely used for the induction and maintenance of anesthesia and for sedation in the intensive care unit. Propofol also possess anti-cancer properties in addition to its sedative effects. Cytotoxicity of all the synthesized compounds was examined against human HeLa cancer cell lines. The anti-cancer screening of these novel drug candidates suggest that all of them reported here may be useful for the treatment of cancer as all of them exhibited significant anticancer activity against human HeLa cancer cell lines. The results indicate that these novel drug candidates might represent a new class of anticancer agents.
\end{abstract}

Keywords: Propofol, Anesthetic, Sedative, 10-Undecenoic Acid, Cytotoxicity

\section{Introduction}

Cancer is the leading cause of death among the global population including United States. A recent American Cancer Society statistical survey has concluded that cancer now exceeds heart disease as the top cause of death among Americans below the age of 85 years, responsible for about 47600 fatalities compared with 450,600 deaths yearly from heart disease. Cancer refers to a large number of diseases categorized by unregulated replication (proliferation) and spread (metastasis) of abnormal cells. Surgery, chemotherapy and radiation therapy are the only methods for treating cancer patients. Infact, chemotherapy is the most popular therapeutic method. Therefore, there is a need to develop new anticancer drugs having better efficiency and broad spectrum activity.

2,6-diisopropylphenol or propofol (Figure 1) a shortacting intravenous anesthetic agent [1,2], has gained wide acceptance since its introduction in the late $80 \mathrm{~s}$, not only in operating rooms but also in other departments, due to its several advantages. Apart from its multiple anesthetic advantages, it has been reported recently that propofol exerts a number of non-anesthetic effects. It is a potent antioxidant [3-5] and has been shown to stimulate protein kinase $\mathrm{C}[6,7]$. It inhibits calcium entry in muscle cells [8] and increase the calcium sensitivity of myofilaments in ventricular myocytes [9]. It decreases cerebral oxygen consumption, reduces intracranial pressure and has potent anti-convulsant properties [10]. It is a potent bronchodilator and has anti-inflammatory properties [11]. It has immunomodulatory analgesic, antiemetic and neuroprotective effects. It also exerts direct inhibitory effects on recombinant cardiac sarcolemmal KATP channels [12]. The antioxidant activity of propofol together with the stimulating effect of protein kinase $\mathrm{C}$ suggests that propofol might have the potential to modulate apoptosis. 3 to $8 \mu \mathrm{g} / \mathrm{ml}$ concentrations of propofol were reported to decrease the metastatic potential of human cancer cells, including HeLa, H71080, HOS and RPMI-7951 cells [13].

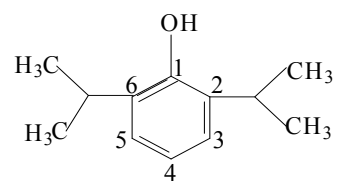

2,6-diisopropylphenol

Figure 1. Structure of 2, 6-diisopropylphenol (propofol). 
Propofol was reported to inhibit pulmonary metastasis of murine osteosarcoma (CM8) cells in mice through the modulation of Rho A [14]. R. Siddiqui et al. [15], studied the effect of two omega-3 fatty acids, docosahexaenoic acid (DHA) and eicosapentaenoic acid (EPA), combined with propofol on a breast cancer cell line in vitro. The results of the study showed that propofol and DHA or EPA has a much more significant effect on cancer cells when used in combination, as conjugates, than when used alone. The conjugates inhibit cancer cell adhesion by $15 \%$ and $30 \%$ respectively, reduce cell migration by $50 \%$ and increase apoptosis by $40 \%$. Harvey et al. [16] reported the characterization and evaluation of novel anti-cancer conjugate, 2, 6-diisopropylphenol-docosa-hexaenoate (PP-DHA) and its analogs on breast cancer cell lines. Results suggested that these novel conjugates and their amide derivatives may be useful for the treatment of breast cancer.

Current trends in the treatment of human cancers favor drug combinations that result in improved responses, where the contributions of a variety of fatty acids have been proved highly significant $[17,18]$ A number of fatty acids are part of our diet; therefore, nutritional dietary supplements highly enriched in certain fatty acid have been suggested to prevent the side effects of cancer therapy $[18,19]$. Certain triglycerides and fatty acids have the potential to prevent or inhibit carcinogenesis [20-23].

10 -undecenoic acid is an eleven-carbon monounsaturated fatty acid, a substance found naturally in the body (occurring in sweat); undecenoic acid is produced commercially by the vacuum distillation of castor bean oil, via the pyrolysis of ricinoleic acid. It is used in the manufacture of pharmaceuticals, cosmetics and perfumery including anti-dandruff shampoos, anti-microbial powders and as musk in perfumes and aromas. It is an inexpensive source for the synthesis of pheromones of cotton pests, peach tree borer and cherry tree borer [24]. It is an economical antifungal agent and is the active ingredient in many topical over-the-counter antifungal preparations. [25] 10-Undecenoic acid has long been known to be fungicidal against Candida albicans, thus helping achieve a healthy balance of normal vaginal and intestinal flora [26]. It is FDA approved in over the counter medications for skin disorders or problems. It is the active ingredient in medications for skin infections, and relieves itching, burning and irritation. It is also used in the treatment of psoriasis [27]. 10-Undecenoic acid is also proven to have antibacterial and anti-viral properties that are effective on viral skin infections such as the Herpes simplex virus $[28,29]$. It has the bifunctionality, odd carbon number and the position of its unsaturated double bond at the end of the chain, makes it a versatile tool for chemical synthesis. Although most studies of 10-Undecenoic acid have concentrated on its anti-fungal, anti-bacterial, antiviral activities, there are a few reports indicating that the derivatives of this compound may also affect cellular processes related to cancer [30,31]. Mustafa et al. [32] reported first synthesis and antitumor evaluation of $\mathrm{F}, \mathrm{N}$, and $\mathrm{S}$ containing $\mathrm{C} 4 \alpha$-fatty acid derivatives of podophyllotoxin. The efficient synthesis of a series of Fatty acid-based derivatives of propofol possessing Sulfur atom (Figure 2) and their significant in vitro selectivity for inhibiting the growth of cancer cells (HeLa cancer cell lines) have been demonstrated here. The results indicate that these novel conjugates might represent a new class of anticancer agents.

\section{Materials and Methods}

A thin layer chromatographic applicator (Toshniwal, India), $20 \times 3.5 \mathrm{~cm}$ glass plates and $24 \times 6 \mathrm{~cm}$ glass jar were used for performing thin layer chromatography (TLC). Silica Gel “G” (E. Merck, India) was used as a stationary phase. Petroleum ether and diethyl ether (1:1, $\mathrm{vol} / \mathrm{vol})$ was used as a developing solvent. Reaction products on TLC plates were visualized by UV light and by exposure to iodine vapors. Column chromatographic separations were performed using silica gel "G" packing of particle size 60-120 mesh (petroleum ether/diethyl ether, $1: 1, \mathrm{v} / \mathrm{v}) . \mathrm{H}^{1} \mathrm{NMR}$ and $\mathrm{C}^{13} \mathrm{NMR}$ spectra were recorded on Advance DRX-200 Bruker, (Switzerland) NMR Spectrometer. Molecular weights were determined by MS route JMS-600H, Jeol (Japan) Mass Spectrometer. FTIR Spectra were recorded in chloroform on a Spectrum RX-1 FTIR, Perkin Elmer Spectrometer. All these analyses were done in CDRI (Central Drug Research Institute, Lucknow), India. 2, 6-diisopropyl phenol (DPP), 4-dimethyl amino pyridine (DMAP) was procured from Acros chemicals. The coupling reagent-N, N-dicyclohexyl carbodiimide (DCC) was purchased from Fluka chemical corporation (New York), 10-undecenoic acid and $\beta$-mercaptoethanol was purchased from Aldrich Chemicals and methylene chloride was purchased from CDH Chemicals (Mumbai, India).

\subsection{Synthesis of Compound, 1-Isopropyl (11'-Mercaptoethanol) Undecanoate (S-1)}

$\beta$-Mercaptoethanol (1 mmol) and 10-undecenoic acid (1 mmol) were dissolved in dry dichloromethane $(5 \mathrm{ml})$ and stirred at room temperature. Progress of reaction was monitored on TLC plates. This reaction showed the formation of single product and was completed in 10 hours. Methylene chloride was rotary- evaporated and the residue was passed through a silica gel column 60-120 mesh particle size, (petroleum ether/diethyl ether, 1:1, v/v; RF $=0.2$ ) to obtain a solid white powder (yield 90\%). To a stirred solution of the above product $(1 \mathrm{mmol})$ in methyl- 
ene chloride (5 ml) was added 2, 6-diisopropyl phenol (1 ture was allowed to stir at room temperature under mmol) and DMAP (catalytic amount). The reaction mix- nitrogen for 10 minutes before DCC ( 1 mmol) was added

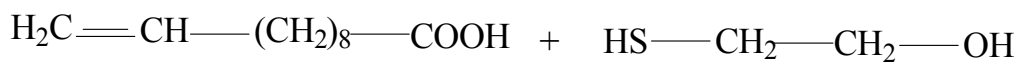

(10- Undecenoic acid)

(2-mercaptoethanol)

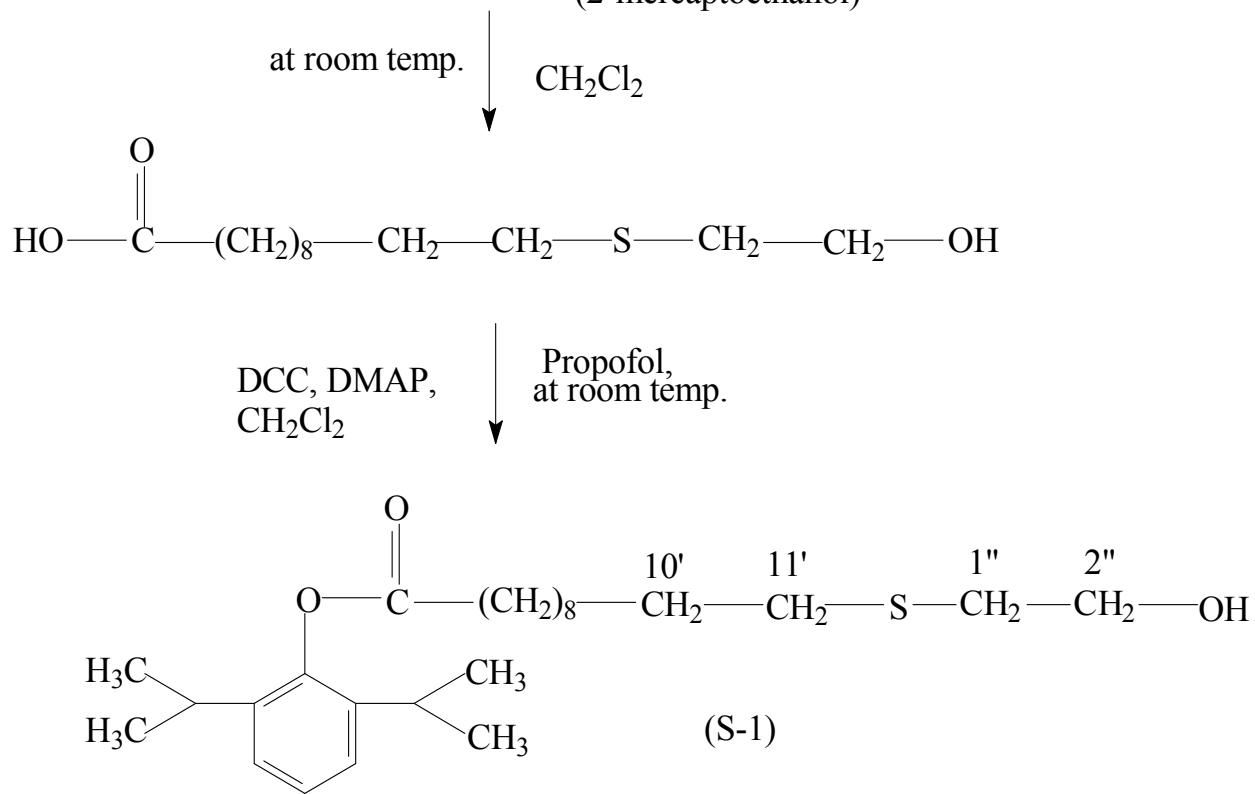

10-Undecenoic acid, DCC, DMAP,

$\mathrm{CH}_{2} \mathrm{Cl}_{2} \quad \checkmark$ at room temp.

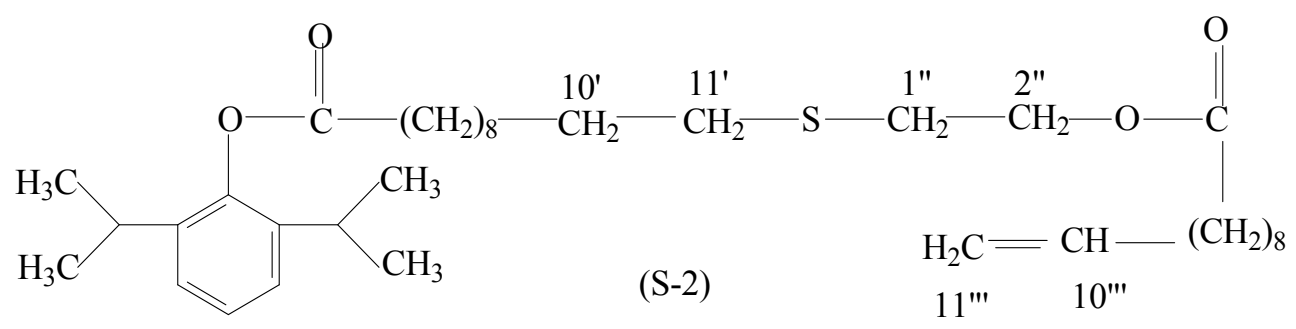

$\mathrm{CH}_{2} \mathrm{Cl}_{2}$, at room temp.<smiles>OCCS</smiles><smiles>CC(C)c1cccc(C(C)C)c1OC(=O)CCCC[Te]C[Te]CO</smiles>

Figure 2. Reaction scheme. 
to it. The reaction mixture was allowed to stir at room temperature. Progress of reaction was monitored on TLC plates. This reaction also showed the formation of single product and was completed in 7 hours. The reaction mixture was filtered to remove solid dicyclohexylurea and the filtrate was evaporated under reduced pressure at $20^{\circ} \mathrm{C}$. The semisolid mass was purified by column chromatography on silica gel, 60-120 mesh particle size, (petroleum ether/diethyl ether, $1: 1$, vol/vol; $\mathrm{RF}=0.8$ ) to obtain S-1 (950 mg, 90\%) as a sticky, viscous, colorless oil.

\subsection{Synthesis of Compound, 1-Isopropyl (11'-Mercaptoethane-Undec-10"'-Enoate)- Undecanoate (S-2)}

Equimolar amounts of the above compound and 10-Undecenoic acid and catalytic amounts of DMAP were dissolved in $5 \mathrm{ml}$ of methylene chloride and stirred at room temperature for 10 minutes before DCC was added to it. The reaction mixture was allowed to stir at room temperature. Progress of reaction was monitored on TLC plates. This reaction also showed the formation of single product and was completed in 12 hours. The reaction mixture was filtered to remove solid dicyclohexylurea, and the filtrate was evaporated and the residue was purified by column chromatography on silica gel, 60-120 mesh particle size (petroleum ether/diethyl ether, 1:1, vol /vol; $\mathrm{RF}=1.0)$ to obtain $\mathrm{S}-2(1.9 \mathrm{~g}, 95 \%)$ as a sticky, viscous, colorless oil.

\subsection{Synthesis of Compound, 1-Isopropyl (11"'-Mercaptoethanol)-11'-Mercaptoethane -Diundecanoate (S-3)}

Equimolar amounts of the above compound and $\beta$-mercaptoethanol were dissolved in $5 \mathrm{ml}$ of dry methylene chloride. The reaction mixture was allowed to stir at room temperature and the progress of reaction was monitored on TLC plates. This reaction also showed the formation of single product and was completed in 6 hours. Methylene chloride was rotary evaporated and the residue was purified by column chromatography on silica, 60-120 mesh particle size (petroleum ether/diethyl ether, 1:1, vol/vol; RF $=0.7)$ to obtain S-3 (1.0 g, 90\%) as a sticky, viscous and colorless oil.

\subsection{Assay for Anti-Cancer Activity}

The compounds S-1, S-2, S-3 were examined for their in vitro cytotoxicity against human cancer cell line HeLa cell lines. The cells were cultured in serum free RPMI1640 medium supplemented with antibiotic solution (60 $\mathrm{mg} / \mathrm{L}$ ), at $37^{\circ} \mathrm{C}, 95 \%$ humidity, $5 \% \mathrm{CO}_{2}$ and sub cultured every 2-3 day using standard cell culture techniques. For the assay, cells from different cell lines were seeded in 6-well plates at a density of $1 \times 10^{6}$ cells/well and were allowed to grow undisturbed for $24 \mathrm{~h}$ before addition of the test compound. Different concentrations of compound were added and cells were further incubated for $24 \mathrm{~h}$. After the incubation time the samples were diluted in RPMI-1640 medium at $37^{\circ} \mathrm{C}$. Cytotoxicity was made by using the trypan blue assay [33] to determine cell viability. The results are summarized in Figure 3.

\section{Results and Discussion}

Here, the efficient synthesis of $\mathrm{C} 1 \alpha$-Fatty acid (FA) analogs of Propofol containing the Sulfur atom has been reported. The terminal double bond (C-11/10) in the side chain of 10-undecenoic acid underwent an efficient addition reaction at $\mathrm{C}-11$ when treated with a slight excess of 2-mercaptoethanol to give a saturated thioether-incor-
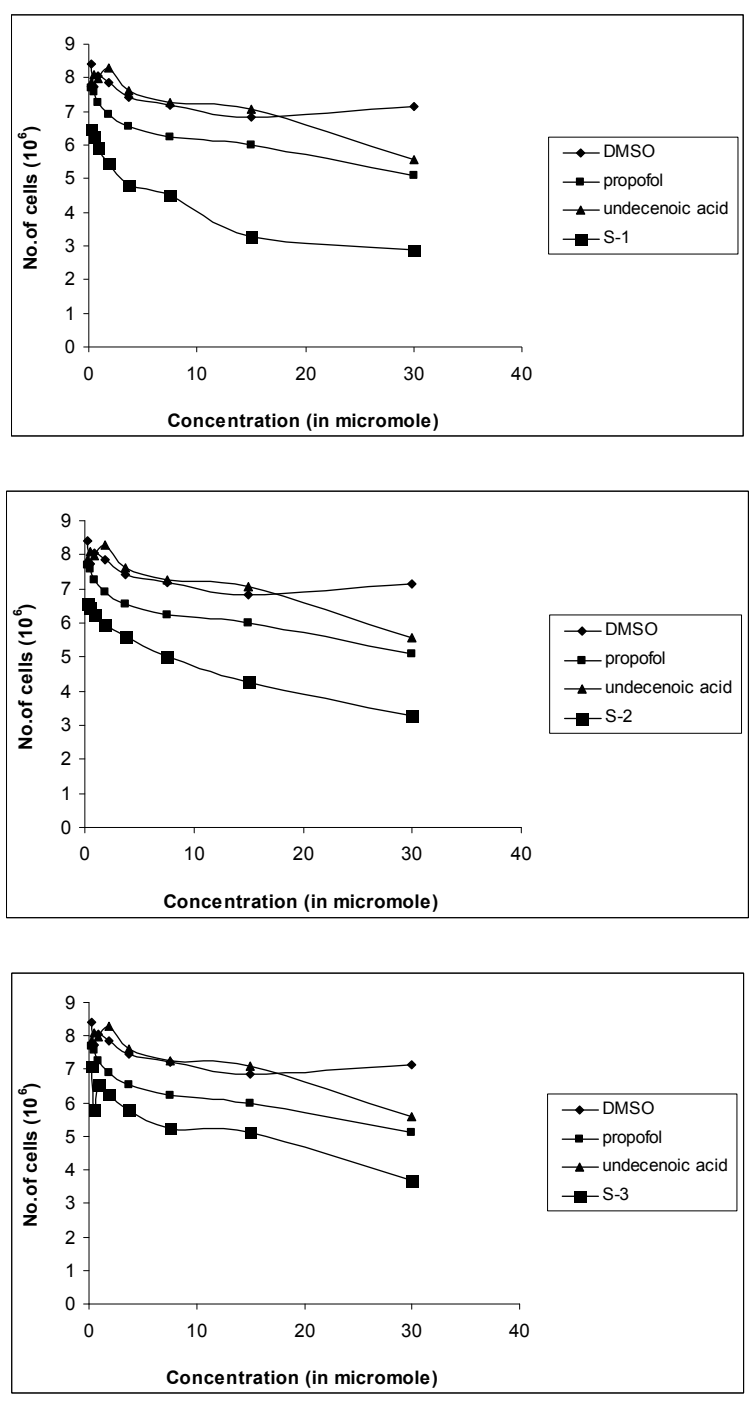

Figure 3. Graphs showing variation of number of viable cells with concentration (in micromole) of S-1, S-2 and S-3. 
porated analog S-1, after reacting with the hydroxyl group of propofol. DCC (N, N-dicyclo hexyl carbodiimide) and DMAP (4-dimethyl amino pyridine) was used to esterify the $1 \alpha$-hydroxy group of propofol with the carboxylic acid group of fatty acid, 10-Undecenoic acid. Similarly, S-2 compound was prepared by the esterification of hydroxyl group of S-1 compound with carboxylic acid group of fatty acid, undec-10-enoic acid in the presence of DCC and DMAP. Then, S-3 compound was synthesized by the addition reaction at the terminal double bond (C-11"'"/10"') in the side chain of compound $\mathrm{S}-2$ when treated with the slight excess of 2-mercaptoethanol. The reaction scheme is shown as Figure 2. The stereochemistry of all the stereogenic centers (C-1 of propofol, C-11' of fatty acid unit, C-2" of 2-mercaptoethanol and C-11" " of second unit of fatty acid) at which the coupling reactions took place, was retained. Spectroscopic data established their chemical structures and are summarized in experimental section.

The IR spectra of compound S-1 show a strong and broad absorption bands at 1738.2 and $1165.3 \mathrm{~cm}^{-1}$ which are attributable to $\mathrm{C}=\mathrm{O}$ and $\mathrm{C}-\mathrm{O}$ bands respectively, and indicate the presence of an ester. The carbon signals at $\delta C 156.76$ and 173.63 confirmed the presence of an ester group. A strong band at $3034.8 \mathrm{~cm}^{-1}$ is characteristic of an aromatic C-H (propofol) and the band at 2930.4 and $2856.7 \mathrm{~cm}^{-1}$ is characteristic of aliphatic C-H bonds. A strong band at $3361.8 \mathrm{~cm}^{-1}$ confirm the presence of the hydroxyl group $(\mathrm{OH})$ which is further correlated with a carbon signal at $\delta \mathrm{C} \mathrm{70.1.} \mathrm{The} \mathrm{chemical} \mathrm{shifts} \mathrm{for} \mathrm{the}$ three aromatic protons are moved downfield at $\partial \mathrm{H} 6.897$ $(\mathrm{t}, \mathrm{J}=7.6 \mathrm{~Hz}, 1 \mathrm{H}), 7.06(\mathrm{~d}, \mathrm{~J}=7.6 \mathrm{~Hz}, 1 \mathrm{H})$ and $7.14(\mathrm{~d}, \mathrm{~J}$ $=6.4 \mathrm{~Hz}, 1 \mathrm{H})$ and their respective carbon signals appeared at $\delta \mathrm{C} 120.56,123.4$ and 123.83 . For twelve protons of the two isopropyl groups of propofol, two doublets were observed at $\partial \mathrm{H} 0.892(\mathrm{~d}, \mathrm{~J}=6.8 \mathrm{~Hz}, 6 \mathrm{H})$ and $1.20(\mathrm{~d}, \mathrm{~J}=6.8 \mathrm{~Hz}, 6 \mathrm{H})$ and their respective carbon signals appeared at $\delta \mathrm{C} 24.70$ and 24.92. Two multiplets were observed at $\partial \mathrm{H} 2.92(\mathrm{~m}, 1 \mathrm{H})$ and $3.18(\mathrm{~m}, 1 \mathrm{H})$ for the protons of the carbon atoms adjacent to the C-2 and C-6 of propofol. The carbon signals at $\delta \mathrm{C} 27.51$ and 63.35 correspond to 1 " $\mathrm{CH} 2$ and $2 " \mathrm{CH} 2$ and their respective chemical shifts at $\partial \mathrm{H} 2.68(\mathrm{t}, \mathrm{J}=6.0 \mathrm{~Hz}, 2 \mathrm{H}), 3.68(\mathrm{t}$, $\mathrm{J}=6.0 \mathrm{~Hz}, 2 \mathrm{H})$. Signals from 1.26-1.32 (m, 12H) correspond to the $6 \mathrm{X} \mathrm{CH} 2$ ' groups of fatty acid chain, $12 \mathrm{H}$. The chemical shift at $\partial \mathrm{H} 2.04(\mathrm{~m}, 4 \mathrm{H})$ attribute to $3^{\prime} \mathrm{CH} 2$ and $9^{\prime} \mathrm{CH} 2$. Similarly at $\partial \mathrm{H} 2.34(\mathrm{~m}, 2 \mathrm{H})$ relate to $2^{\prime} \mathrm{CH} 2$ of fatty acid chain and chemical shift at $\partial \mathrm{H} 2.58(\mathrm{t}, \mathrm{J}=$ $7.6 \mathrm{~Hz}, 2 \mathrm{H})$ correspond to $11^{\prime} \mathrm{CH} 2$ of fatty acid chain.

The IR spectra of compound S-2 show a broad and strong band at $1718.2 \mathrm{~cm}^{-1}$ and $1216 \mathrm{~cm}^{-1}$ correspond to the $\mathrm{C}=\mathrm{O}$ and $\mathrm{C}-\mathrm{O}$ bands respectively, and indicate the presence of an ester group which is correlated to the car- bon signals at $\delta \mathrm{C} 172.3$ and 173.56 that confirmed the presence of two carbonyl groups (ester and estolide carbonyls). Estolides are a group of FA polyesters resulting from ester bond formation between the oxygen of a hydroxyl group of one FA and the carbonyl carbon of the terminal carboxylic group of another FA. A distinct absorption band at $1642.3 \mathrm{~cm}^{-1}$ represent alkenes which is further confirmed by the chemical shifts of the olefin protons $(10 " ' \mathrm{H}$ and 11 "' $\mathrm{H})$ at $\partial \mathrm{H} 4.95(\mathrm{~m}, 2 \mathrm{H}), 5.78$ $(\mathrm{m}, 1 \mathrm{H})$ and their respective carbon signals at $\delta \mathrm{C} 126.34$ and 133.79. A strong band at $3020.1 \mathrm{~cm}^{-1}$ is characteristic of an aromatic C-H (propofol) and the band at 2930.4 and $2855.2 \mathrm{~cm}^{-1}$ is characteristic of aliphatic $\mathrm{C}-\mathrm{H}$ bonds. Absence of absorption band at $2555 \mathrm{~cm}^{-1}(-\mathrm{SH})$ attributed to the cleavage of $-\mathrm{SH}$ bond and the formation of new bond. The chemical shifts for aromatic protons are moved downfield at $\partial \mathrm{H} 6.90(\mathrm{t}, \mathrm{J}=7.5 \mathrm{~Hz}, 1 \mathrm{H}), 7.07(\mathrm{~d}$, $\mathrm{J}=7.5 \mathrm{~Hz}, 1 \mathrm{H}), 7.16(\mathrm{~d}, \mathrm{~J}=6.9 \mathrm{~Hz}, 1 \mathrm{H})$ with their respective carbon signals at $\delta \mathrm{C} 120.53,123.36$ and 123.81 . For twelve protons of the two isopropyl groups two doublets were observed at $\partial \mathrm{H} 1.18(\mathrm{~d}, \mathrm{~J}=6.9 \mathrm{~Hz}, 12 \mathrm{H})$ and their carbon signals appear at $\delta \mathrm{C} 23.68$ and 24.68 respectively. Two multiplets were observed at $\partial \mathrm{H} 2.9(\mathrm{~m}, 1 \mathrm{H})$, $3.20(\mathrm{~m}, 1 \mathrm{H})$ for the protons of the carbon atoms that are adjacent to the C-2 and C- 6 of propofol which is further confirmed by their respective carbon signals at $\delta \mathrm{C} 25.52$ and 25.1. Two significant signals at $\delta \mathrm{C} 27.49$ and 63.35 correspond to $1 " \mathrm{CH} 2$ and $2 " \mathrm{CH} 2$ and their respective chemical shifts appear at $\partial \mathrm{H} 2.64(\mathrm{t}, \mathrm{J}=6.0 \mathrm{~Hz}, 2 \mathrm{H})$ and $3.87(\mathrm{t}, \mathrm{J}=6.0 \mathrm{~Hz}, 2 \mathrm{H})$. Signals from $\partial \mathrm{H} 1.25-1.38(\mathrm{~m}$, $20 \mathrm{H})$ correspond to the $6 \mathrm{X} \mathrm{CH} 2$ " and $4 \mathrm{X} \mathrm{CH} 2$ " " of fatty acid methylene chain, $20 \mathrm{H}$.

The IR spectra of compound S-3 show a broad and strong absorption band at $1736.6 \mathrm{~cm}^{-1}$ and $1165.3 \mathrm{~cm}^{-1}$ which are attributable to $\mathrm{C}=\mathrm{O}$ and $\mathrm{C}-\mathrm{O}$ bands respectively, and indicate the presence of an ester. The carbon signals at $\delta \mathrm{C} 167.76$ and 170.1 characterized the presence of two carbonyl groups (ester and estolide carbonyls). A strong band at $3073.9 \mathrm{~cm}^{-1}$ is characteristic of an aromatic C-H (propofol) and the bands at 2930.2 and $2857.1 \mathrm{~cm}^{-1}$ is characteristic of aliphatic C-H bonds. A strong band at $3409.8 \mathrm{~cm}^{-1}$ confirmed the presence of a hydroxyl group and its respective carbon signal appeared at $\delta \mathrm{C}$ 69.12. The chemical shifts for the three aromatic protons are moved downfield at $\partial \mathrm{H} 6.576(\mathrm{~d}, \mathrm{~J}=5.4 \mathrm{~Hz}$, $1 \mathrm{H}), 6.8(\mathrm{t}, \mathrm{J}=7.5 \mathrm{~Hz}, 1 \mathrm{H}), 7.06(\mathrm{~d}, \mathrm{~J}=7.5 \mathrm{~Hz}, 1 \mathrm{H})$ and their respective carbon signals at $\delta \mathrm{C} 120.56,123.4$ and 123.86. For twelve protons of the two isopropyl groups two doublets were observed at $\partial \mathrm{H} 1.18(\mathrm{~d}, \mathrm{~J}=6.9 \mathrm{~Hz}, 1 \mathrm{H})$ and $1.25(\mathrm{~d}, \mathrm{~J}=6.9 \mathrm{~Hz}, 1 \mathrm{H})$ and their respective carbon signals appeared at $\delta \mathrm{C} 24.67$ and 24.87. Two multiplets were observed at $\partial \mathrm{H} 2.9(\mathrm{~m}, 1 \mathrm{H})$ and $3.179(\mathrm{~m}, 1 \mathrm{H})$ for the protons of the carbon atoms that are adjacent to the 
C-2 and C-6 of propofol which is further confirmed by their respective carbon signals at $\delta \mathrm{C} 26.33$ and 25.52 . Two significant signals at $\delta \mathrm{C} 27.49$ and 63.4 correspond to 1 "CH2, 1"'"CH2 and 2"CH2, 2""'CH2 and their respective chemical shifts appear at $\partial \mathrm{H} 2.73$ (double $\mathrm{t}, \mathrm{J} 1=$ $6 \mathrm{~Hz}, \mathrm{~J} 2=6.2 \mathrm{~Hz}, 4 \mathrm{H})$ and $3.73(\mathrm{t}, \mathrm{J}=6 \mathrm{~Hz}, 2 \mathrm{H}), 3.89$ $(\mathrm{m}, 2 \mathrm{H})$. Signals from 1.25 to $1.41(\mathrm{~m}, 24 \mathrm{H})$ correspond to the $6 \mathrm{X} \mathrm{CH} 2$ "' and $6 \mathrm{X} \mathrm{CH} 2$ "' groups of fatty acid methylene chain, $24 \mathrm{H}$.

\subsection{In-Vitro Anti-Cancer Activity}

The compounds S-1, S-2, S-3 were examined for its in vitro cytotoxicity against human cancer cell line HeLa cell lines. A number of studies have concluded that chemically modified FA molecules possess more specific and potent biological activity with possible changes in their therapeutic targets [34]. The present work is based on the chemically transformed FA analogs of propofol. The growth inhibition graphs of S-1, S-2 and S-3 are shown in Figure 3.

All of these analogs showed promising cytotoxicity against human HeLa cancer cells tested. The FA-S-ether analog, i.e., S-1, was functionalized with a fatty acid moiety (C-11) at $\mathrm{C} 1 \alpha$ of propofol, which a close resemblance to the $\omega$-hydroxy fatty acids has showed promising anti-cancer activity against human HeLa cancer cell lines. Mustafa et al. [35] reported that $\omega$-hydroxy fatty acid analogs are excellent growth inhibitors of tumor and their anticancer activity increases with a decrease in the chain length of fatty acid. Same is the case here, S-1 and S-3 both possessed hydroxyl group just like $\omega$-hydroxy fatty acids, but S-1 is more cytotoxically active than S-3. This is because of the reason that compound S-1 has got shorter fatty acid chain length as compared to compound S-3 which has longer chain length of fatty acid and hence comparatively possessed lesser anticancer activity than S-1. Compound S-2 showed more significant anti-cancer activity as compared to S-3 as it possessed terminal double bond in its fatty acid side chain. It showed significantly high growth inhibition activity in the HeLa cancer cell line. Both S-1 and S-2 were excellent growth inhibitors of HeLa cancer cell lines and S-3 is the least active analog of propofol.

The present investigations have indicated that the presence of hydroxyl group and unsaturation may be responsible for such activity. The above results demonstrated that all of these propofol FA conjugates (S-1, S-2, and S-3) not only inhibited cellular proliferation of $\mathrm{HeLa}$ cells but also decreased their viability which was confirmed by cell viability assay using trypan blue dye exclusion method. These results suggest that the propofolfatty acid conjugates possessing Sulfur atom are far more effective at inducing apoptosis in HeLa cancer cells than are the unconjugated parent compounds, i.e., 2, 6-diisopropyl phenol and 10-undecenoic acid.

\section{Conclusions}

The spectral analysis and anti-cancer screening of these novel compounds suggest that all of them reported here may be useful for the treatment of cancer as all of them show significant anticancer activity against human HeLa cancer cell lines. The conjugates are far more active than the parent compounds and possess unique anticancer activity. These novel drug candidates might represent a new class of anti-cancer agents. Further investigations of these novel fatty acid conjugates of propofol may provide useful leads in the development of new and effective pharmaceutical products. Experiments are under way to test these conjugates on different cancer cells lines and also in model systems in vivo.

\section{Acknowledgements}

We are thankful to the Chairman, Department of Applied Chemistry, Faculty of Engineering and Technology, for providing all the facilities and support. We would also like to thank Mr. Azmat Khan, Interdisciplinary Biotechnology Unit, A.M.U. Aligarh for helpful cytotoxic assays and CDRI, Lucknow for providing spectral data.

\section{REFERENCES}

[1] H. Covington, "Use of Propofol for Sedation in the ICV," Critical Care Nursing, Vol. 18, No. 5, 1998, pp. 34-39.

[2] R. D. Miller, "Local Anesthetics: Anesthesia," In: R. D. Miller, Ed., Local Anesthetics, Churchill Livingstone, New York, Vol. 5, 2000, pp. 491-521.

[3] O. Eriksson, P. Pollesello and N. E. Seris, "Inhibition of Lipid Peroxidation in Isolated Rat Liver Mitochondria by the General Anesthetic Propofol," Biochemical Pharmacology, Vol. 44, No. 2, 1992, pp. 391-393.

[4] P. G. Murphy, D. S. Myers, M. J. Davies, N. R. Webster and J. G. Jones, "The Antioxidant Potential of Propofol," British Journal of Anesthesia, Vol. 68, No. 6, 1992, pp. 613-618.

[5] M. Tsuchiya, A. Asada, K. Maeda, Y. Ueda, E. F. Sato, M. Shindo and M. Inove, "Propofol versus Medazolam Regarding their Antioxidant Activities," American Journal of Respiratory and Critical Care Medicine, Vol. 163, No. 1, 2001, pp. 26-31.

[6] H. C. Hemming and A. I. Adamo, "Effects of Halothane and Propofol on Purified Brain Protein Kinase C Activation," Anesthesiology, Vol. 81, No. 1, 1994, pp. 147-155.

[7] N. Kanaya, B. Gable, P. A. Murray and D. S. Damron, "Propofol Increases Phosphorylation of Troponin 1 and Myosin Light Chain via Protein Kinase C Activation in Cardiomyocytes," Anesthesiology, Vol. 98, No. 6, 2003, pp. 1363-1371.

[8] M. Horibe, I. Kondo, D. S. Damron and P. A. Murray, 
"Propofol Attenuates Capacitatine Calcium Entry in Pulmonary Artery Smooth Muscle Cells," Anesthesiology, Vol. 95, No. 3, 2001, pp. 681-688.

[9] N. Kanaya, P. A. Murray and D. S. Damron, "Propofol Increases $\mathrm{Ca}^{2+}$ Sensitivity and Intracellular $\mathrm{pH}$ via Activation of $\mathrm{Na}^{+}-\mathrm{H}^{+}$Exchange in Rat Ventricular Myocytes," Anesthesiology, Vol. 94, No. 6, 2001, pp. 10961104.

[10] Y. Shin, S. Urano and T. Endo, “Antioxidant Property of Propofol and Related Monomeric and Dimeric Compounds," Chemical and Pharmaceutical Bulletin, Vol. 53, No. 3, 2005, pp. 344-346.

[11] P. E. Marik, "Propofol Therapeutic Indications and SideEffects," Current Pharmaceutical Design, Vol. 10, No. 29, 2004, pp. 3639-3649.

[12] V. Ioanna, X. Theodoros, K. Eleni, P. Despoina, K. Chris, K. Athanasius and P. Lila, "Propofol: A Review of its Non-Anesthetic Effects," European Journal of Pharmacology, Vol. 605, No. 1-3, 2009, pp. 1-8.

[13] T. Mammoto, M. Mukai, A. Mammoto, Y. Yamanaka, Y. Hayashi, T. Mashimo, Y. Kishi and H. Nakamura, "Intravenous Anesthetic, Propofol Inhibits Invasion of Cancer Cells," Cancer Letter, Vol. 184, No. 2, 2002, pp. 165170.

[14] K. Atsuko, I. Takefumi and S. Koh, "Enhancement of Anti-Tumor Immunity after Propofol Treatment in Mice," Immuno Pharmacology and Immunotoxicology, Vol. 29, No. 3-4, 2004, pp. 477-486.

[15] R. A. Siddiqui, M. Zerouga, M. Wu, A. Castillo, K. Harvey, G. P. Zaloga and W. Stillwell, "Anti-Cancer Properties of Propofol-Docosahexaenoate and Propofoleicosapentaenoate on Breast Cancer Cells," Breast Cancer Research, Vol. 7, No. 5, 2005, pp. 645-654.

[16] K. A. Harvey, Z. Xu, P. Whitley, V. J. Davisson and R. A. Siddiqui, "Characterization of Anti-Cancer Properties of 2,6-Diisopropylphenoldocosahexaenoate and Analogues in Breast Cancer Cells," Bioorganic and Medicinal Chemistry, Vol. 18, No. 5, 2010, pp. 1866-1874.

[17] J. A. Monendez, S. Ropero, R. Lupu and R. Colomer, "n-6 PUFA $\gamma$-Linolenic Acid (18: 3n-6) Enhances Docetaxel (Taxotere) Cytotoxicity in Human Breast Carcinoma Expression," Oncology Reports, Vol. 11, No. 6, 2004, pp. 1241-1252.

[18] M. P. Moyer, W. E. Hardman and I. Canceron, "Accelerated Action Fatty Acid (AAFA) Promotes Health of Normal Tissues and Minimizes the Toxic Side Effects of Chemotherapy," U.S. Patent, 102907, 2002.

[19] W. E. Hardman, I. L. Cameron and M. P. Moyer, "Fatty Acids to Minimize Cancer Therapy Side Effects," $P C T$ International, WO-US16666 0722, 1999.

[20] S. C. Larsson, M. Kumlin, M. Ingelman-Sundberg and A. Wolk, "Dietary Longchain n-3 Fatty Acids for the Prevention of Cancer: A Review of Potential Mechanisms," American Journal of Clinical Nutrition, Vol. 79, No. 6, 2004, pp. 935-945.

[21] K. A. Conklin, "Dietary PUFA: Impact on Cancer Chemotherapy and Radiation," Alternative Medicine Review:
A Journal of Clinical Therapeutic, Vol. 7, No. 1, 2002, pp. 4-21.

[22] P. Bougnoux, "n-3 PUFAs and Cancer," Current Opinion in Clinical Nutrition and Metabolic Care, Vol. 2, No. 2, 1999, pp. 121-126.

[23] R. Berge, "Fatty Acid Analogues for the Treatment of Cancer," PCT International, WO-NO301 20010713, 2001.

[24] S. Pawar and S. Chattopadhyay, "10-Undecenoic Acid an Inexpensive Source for the Synthesis of the Pheromones of Cotton Pests, Peach Tree Borer and Cherry Tree Borer," Molecules, Vol. 2, No. 6, 1997, pp. 87-90.

[25] L. Shapiro and S. Rothman, "Undecylenic Acid in the Treatment of Dermatomycoses," Archives of Dermatology and Syphilology, Vol. 52, No. 3, 1945, pp. 166-171.

[26] N. Mc Lain, R. Ascanio and C. Baker, "Undecylenic Acid Inhibits Morphogenesis of Candida Albicans," Antimicrobial Agents and Chemotherapy, Vol. 44, No. 10, 2000, pp. 2873-2875.

[27] L. P. Ereaux and G. E. Craig, "Undecylenic Acid in Psoriasis," Canadian Medical Association Journal, Vol. 61, No. 4, 1949, pp. 361-364.

[28] N. Bourne, J. Ireland, L. R. Stanberry and D. I. Bemstein, "Effect of Undecylenic Acid as a Topical Microbicide against Geniotal Herpes Infection in Mice and Guinea Pigs," Antiviral Research, Vol. 40, No. 3, 1999, pp. 139 144.

[29] S. D. Shafran, S. L. Sacks and F. Y. Aoki, "Topical Undecylenic Acid for Herpes Simplex Labiatus: A Multicenter, Placebo-Controlled Trial," Journal of Infectious Diseases Infect Diseases, Vol. 176, No. 1, 1997, pp. 78-83.

[30] V. P. M. Rahman, S. Mukhtar, W. H. Ansari and G. Lemiere, "Synthesis, Stereochemistry and Biological Activity of Some Novel Long Chain Substituted Thiazolidin4-Ones and Thiazan-4-One from 10-Undecenoic Acid Hydrazide," European Journal of Medicinal Chemistry, Vol. 40, No. 4, 2005, pp. 173-184.

[31] T. Yutaka, K. Masaru, R. Takao, Y. Shusaku and Y. Kenji, "Enzymatic Synthesis of Arbutin Undecylenic Acid Ester and its Inhibitory Effect on Melanin Synthesis," Bioorganic and Medicinal Chemistry Letters, Vol. 17, No. 15, 2007, pp. 894-960.

[32] J. Mustafa, S. I. Khan, G. Ma, L. A. Walker and I. A. Khan, "Synthesis, Spectroscopic and Biological Studies of Novel Estolides Derived from Anti-Tumor Active 4-O-Podophyllotoximyl 12-Hydroxyl Octadec-Z-9 Enoate," Lipids, Vol. 39, No. 6, 2005, pp. 659-666.

[33] P. R. Roper and B. Drewinko, "Comparision of in Vitro Methods to Determine Drug Induced Cell Lethality," Cancer Research, Vol. 36, No. 7, 1976, pp. 2182-2188.

[34] K. J. Tronstad, K. Berge, R. K. Berge and O. Bruserud, "Modified Fatty Acids and their Possible Therapeutic Targets in Malignant Diseases," Expert Opinion on Therapeutic Targets, Vol. 7, No. 5, 2003, pp. 663-677.

[35] J. Mustafa, S. I. Khan, G. Ma, L. A. Walker and I. A. Khan, "Synthesis and Anticancer Activities of FA Analogs of Podophyllotoxin," Lipids, Vol. 39, No. 2, 2004, pp. 167-172. 